\title{
Cremation Challenge Under Coronavirus Disease-2019
}

\author{
(1) Sunny Chi Lik Au \\ Pamela Youde Nethersole Eastern Hospital, Clinic of Special Out Patient, Hong Kong, China
}

\section{Dear Editor,}

World Health Organization declared Coronavirus disease-2019 (COVID-19) a pandemic on 11/3/2020. The number of COVID-19 infected cases exceeded 12 million worldwide, and 570 thousand of them were died by 4 months after the declaration. Previously a taboo subject, death is now a topic of ordinary conversation under COVID-19.

Geriatricians are now used to the fact that older persons with comorbidities were the most likely to die from COVID-19 (1), and deceased relatives are now finding no place for burial under the sudden surge in demand. Cremation becomes the trend (2), yet its safety issue on medical implants warrant attention by caring practitioners. Despite seldom implanting medical devices to patients, geriatricians are familiar with potential contraindications to cremation, such as pacemaker and radioactive implants, as we are used to accompanying patients' last journey.

Pacemaker, including implantable cardioverter-defibrillator, is an electronic device that saved millions of lives since its inventory more than half a century ago (3). Indications of a pacemaker are not uncommon among geriatric patients, including symptomatic bradycardia, long OT syndrome, advanced $2^{\text {nd }}$ or $3^{\text {rd }}$-degree heart block, and certain types of cardiomyopathy (4). For the internal type of pacemaker installed through subcutaneous implantation, it could be easily inspected or palpated upon physical examination over the chest wall, or on basic chest radiography (Figure 1). Being an electronic device with a battery in situ, the pacemaker runs the risk of explosion upon burning in the cremator, in which the risk is even higher with advancing battery design (5).

Radioactive sources are sometimes implanted into the body as a local cancer treatment in modern medicine. Examples are gold-198 (Au198), iodine-125 ([125), iodine-131 (1131), radium-223 (Ra223), and yttrium-90 (Y90), which are used as radiopharmaceuticals for head and neck (Figure 2), lung, prostate, cervix cancer, hepatocellular carcinoma, or choroidal melanoma etc. Most of the above mentioned are of short halflives of less than 15 days, except I125 which has a half-life of 60 days. Prostate implant with radioactive 1125 was gaining popularity in the last few decades, and its radiation risks towards staff for patients or persons living close to patients are well addressed. Although cremation of radiation seeds poses minimal harm to the public after dilution by air, it carries some risks to those handling the cremated remains (6). In general, cremation

Chest radiography in anteroposterior view

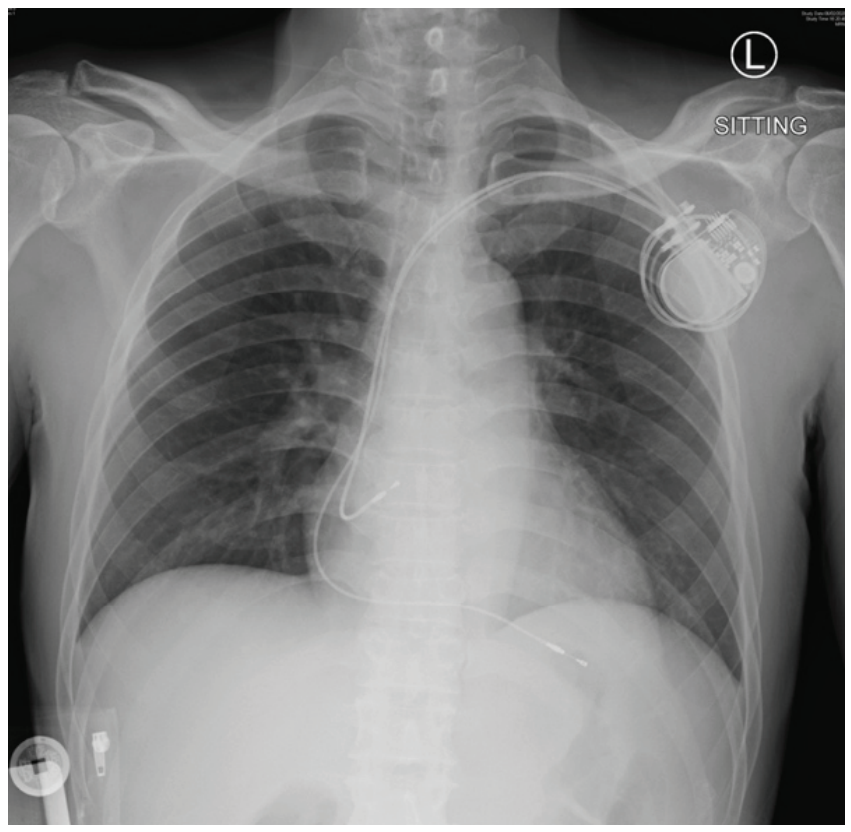

Figure 1. Pacemaker battery and main bulk was seen below the left clavicle, with electrode leads placed at AV node and ventricle

AV: Atrioventricular

Address for Correspondence: Sunny Chi Lik Au, Pamela Youde Nethersole Eastern Hospital, Clinic of Special Out Patient, Hong Kong, China Phone: +852 21626909 E-mail: kilihcua@gmail.com ORCID: orcid.org/0000-0002-5849-3317

Received: 13.05.2020 Accepted: 28.09.2020

Cite this article as: Au SCL. Cremation Challenge Under Coronavirus Disease-2019. Eur J Geriatr Gerontol 2021;3(1):29-31

๑Copyright 2021 by the Academic Geriatrics Society / European Journal of Geriatrics and Gerontology published by Galenos Publishing House. 
Computed tomography scan of the orbit in transverse cut

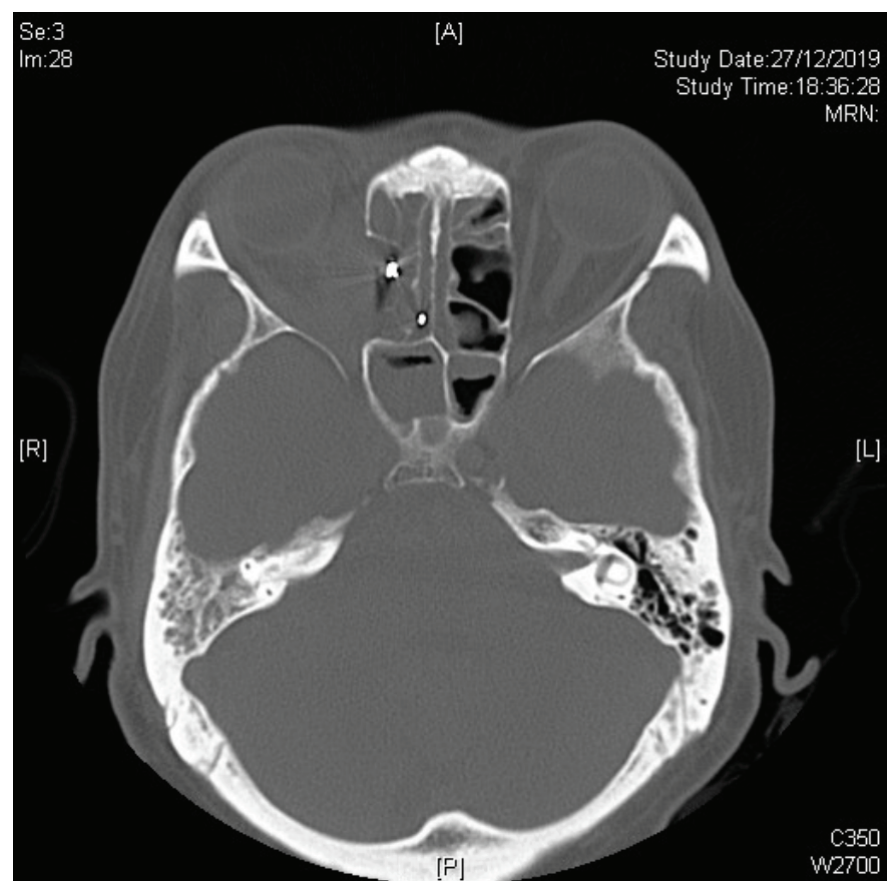

Figure 2. Two radiopaque radioactive seeds (with streak artifacts) were seen at the level of ethmoid sinus, they were implanted for metastatic sinus sarcomatoid carcinoma after repeated surgery and external beam radiotherapy

is contraindicated to bodies with the radioactive implants, and burial is suggested or even required by local legislations. Different countries have different restrictions on burial timing, and usually 10-15 half-lives are required for patients with longlasting radioactive source implantation, e.g. 24 months for the |125 mentioned above.

Last but not least, gold weight implant is sometimes explanted from the deceased before cremation (Figure 3), not of safety but for financial concern. Patients who suffered from paralytic lagophthalmos, mainly from facial nerve palsy, would benefit from gold weight implantation over the upper eyelid to correct the lagophthalmos, thus preventing exposure keratopathy (Figure 4). Standard eyelid gold weight ranges from 1-2.5 gram, which values differently towards deceased relatives.

In conclusion, cremation demand is increasing under COVID-19. Implanted electronic devices like pacemaker, and radioactive implants warrant removal from the dead body before proceeding to safe cremation.

Keywords: Cremation, coronavirus, pacemaker, radiopharmaceuticals, computed tomography

\section{Ethics}

Peer-review: Externally and internally peer-reviewed.

Financial Disclosure: The author declared that this study received no financial support.
Clinical photo of an explanted gold weight from eyelid

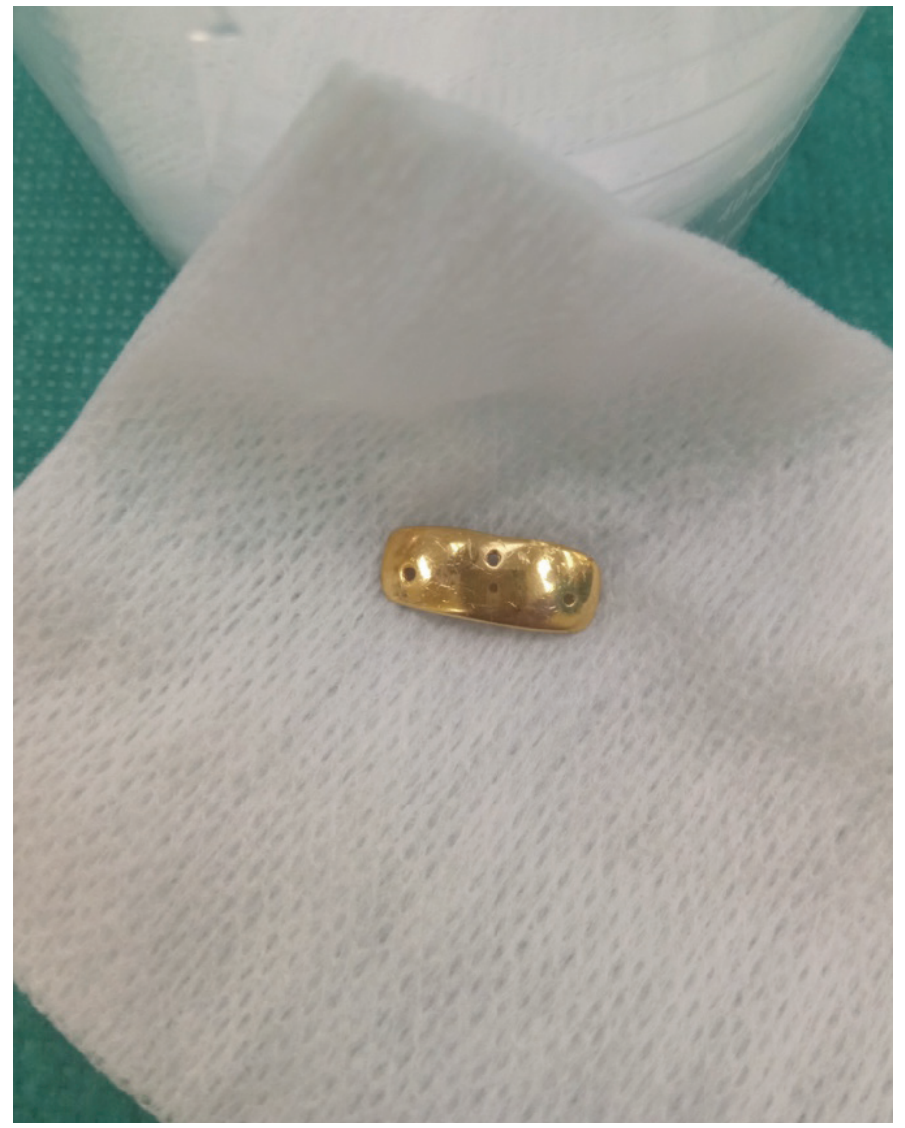

Figure 3. The gold weight was in curved shape conforming the shape of the normal eyelid. There are few $1 \mathrm{~mm}$ sized holes on top for suture needle to pass intra-operatively

Computed tomography scan of the orbit in transverse cut

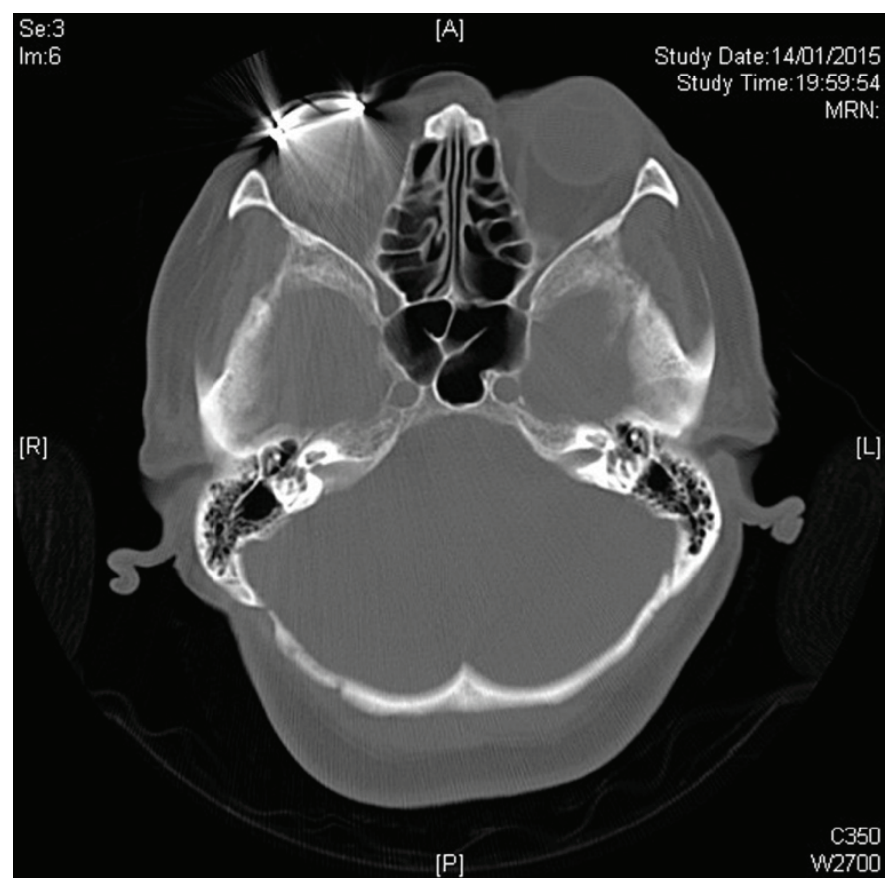

Figure 4. Right upper lid gold weight was in situ causing significant streak artifact 


\section{References}

1. Abbatecola AM, Antonelli-Incalzi R. Editorial: COVID-19 Spiraling of Frailty in Older Italian Patients. J Nutr Health Aging 2020;24:453-455.

2. Postill G, Murray R, Wilton A, Wells RA, Sirbu R, Daley MJ, Rosella LC. An analysis of mortality in Ontario using cremation data: Rise in cremations during the COVID-19 Pandemic. medRxiv 2020;1-15.

3. van Hemel NM, van der Wall EE. 8 October 1958, D Day for the implantable pacemaker. Neth Heart J 2008;16:1-2.

4. Kotsakou M, Kioumis I, Lazaridis G, Pitsiou G, Lampaki S, Papaiwannou A, Karavergou A, Tsakiridis K, Katsikogiannis N, Karapantzos I, Karapantzou C, Baka S, Mpoukovinas I, Karavasilis V, Rapti A, Trakada G, Zissimopoulos A, Zarogoulidis K, Zarogoulidis P. Pacemaker insertion. Ann Transl Med 2015;3:42.

5. Gale $\mathrm{CP}$, Mulley GP. Pacemaker explosions in crematoria: problems and possible solutions. J R Soc Med 2002;95:353-355.

6. Que W. Radiation safety issues regarding the cremation of the body of an I-125 prostate implant patient. J Appl Clin Med Phys 2001;2:174-177. 